\title{
Analisis Quality of Service Routing MPLS OSPF Terhadap Gangguan Link Failure \\ Analysis of Service Quality for Routing MPLS OSPF Against Link Failure Interference
}

\author{
Arief Budiman ${ }^{1}$, Adi Sucipto ${ }^{2}$, Anas Rosyid Dian ${ }^{3}$ \\ ${ }^{1,2,3}$ Fakultas Teknik dan Ilmu Komputer,Universitas Teknokrat Indonesia \\ E-mail: ${ }^{1}$ arief.budiman10@teknokrat.ac.id, ${ }^{2}$ adi.sucipto@ @eknokrat.ac.id, \\ 3anas_rosyid_dian@teknokrat.ac.id
}

\begin{abstract}
Abstrak
Penerapan metode routing dalam kegiatan yang menggunakan jaringan komputer dalam lingkup besar diperlukan oleh administrator jaringan, agar dapat melakukan pengoptimalan lauyanan jaringan. Pemilihan metode routing akan membantu dalam mewujudkan perkembangan jaringan yang baik, namun dibutuhkan metode routing yang memiliki kinerja bagus tidak hanya dalam kondisi jaringan yang baik tapi juga pada kondisi jaringan yang mengalami gangguan. Salah satu metode yang memiliki kemampuan yang baik dalam jaringan yang semakin besar adalah Multiprotocol Lable Switching (MPLS), dan dapat dikombinasikan dengan protokol Open Shortest Path First (OSPF). Tujuan penerapan metode MPLS OSPF adalah untuk melihat bagaimana metode tersebut melakukan pengiriman data dalam berbagai kondisi. Tentunya agar membuat jaringan menjadi lebih baik kinerjanya dalam mengirimkan paket data, dengan mencari rute atau jalur yang terbaik pada topologi jaringan. Penelitian ini akan mengimplementasikan metode routing MPLS OSPF kedalam beberapa bentuk topologi jaringan berupa prototipe, dengan memberikan skenario pengujian berupa gangguan pemutusan link atau link failure. Pengujian dianalisa menggunakan tools Wireshark. Hasil yang didapat pada penelitian ini menunjukkan bahwa metode routting MPLS OSPF menunjukkan hasil yang baik dalam menangani gangguan, dengan nilai parameter QoS yang tergolong dalam kategori baik. Nilai throughput didapat mengalami penurunan besar nilai pada kondisi gangguan link failure.
\end{abstract}

Kata kunci:Gangguan, MPLS OSPF, QoS, Wireshark.

\begin{abstract}
The application of the routing method in activities that use computer networks in a large scope is required by network administrators, in order to optimize network services. The selection of a routing method will help in realizing a good network development.However, it requires a routing method that has good performance not only in good network conditions but also in network conditions that are experiencing disruption. One method that has good capabilities in an increasingly large network is Multiprotocol Lable Switching (MPLS), and can be combined with the Open Shortest Path First (OSPF) protocol. The purpose of implementing the MPLS OSPF method is to see how this method transmits data in various conditions. Of course, in order to make the network better performance in sending data packets, by finding the best route or path in the network topology. This study will implement the MPLS OSPF routing method into several forms of network topology in the form of a prototype, by providing a test scenario in the form of a link break or link failure. The test is analyzed using Wireshark tools. The results obtained in this study indicate that the MPLS OSPF routting method shows good results in handling disturbances, with QoS parameter values that are in the good category. The throughput value obtained has a large decrease in the value of the link failure condition.
\end{abstract}

Keywords: Crashes, MPLS OSPF, QoS, Wireshark 


\section{PENDAHULUAN}

Perkembangan infrastruktur jaringan di suatu tempat tentunya akan membuat topologi atau infrastruktur jaringan berkembang. Seiring perubahan tersebut, kebutuhan akan performa jaringan yang baik, harus mengimbangi demi menunjang aktifitas dan memberikan kenyamanan pada pengguna jaringan. Perubahan jaringan komputer dari jaringan yang sederhana menjadi jaringan yang lebih besar membutuhkan perencanaan yang baik, salah satunya dengan level pengelolaan router yang baik.Pengelola jaringan harus bisa memberikan kenyamanan bagi pengguna dengan metode routing yang tepat. Pemilihan protokol routing dalam pembangunan dan desain jaringan diperlukan untuk menyediakan pemulihan lalu lintas data [1]. Kondisi jaringan sejatinya diharapkan memiliki kualitas yang baik pada saat digunakan, namun pada kenyataannya gangguan terhadap jaringan pasti terjadi. Salah satu bentuk gangguan yang terjadi adalah putusnya jalur jaringan atau Link Failure, yang menyebabkan penggunaan jaringan menjadi tidak nyaman.

Salah satu metode yang memiliki kemampuan yang baik dalam jaringan yang semakin besar adalah Multiprotocol Lable Switching (MPLS). MPLS merupakan teknologi yang memiliki kemampuan pengiriman informasi yang menjamin kualitas, skalabilitas, keandalan, dan keamanan paket yang dikirim[2][3]. Dikombinasikan dengan OSPF yang menggunakan algoritma djikstra, yang merupakan algoritma pencarian jalur tercepat [4][5]. Kecenderungan protokol routing ini adalah menemukan jalur jarak paling baik dalam komunikasi dengan nilai cost path lebih rendah yang dihasilkan [3].

MPLS adalah solusi yang dapat disesuaikan untuk mengatasi kesulitan yang dihadapi oleh jaringan saat ini seperti skalabilitas, kualitas manajemen layanan, dan rekayasa lalu lintas [6]. Pemilihan metode routing akan membantu dalam mewujudkan perkembangan jaringan yang baik, namun dibutuhkan metode routing yang memiliki kinerja bagus tidak hanya dalam kondisi jaringan yang baik tapi juga pada kondisi jaringan yang mengalami gangguan.

Penelitian terkait Penelitian oleh Rahmawati dkk yang melakukan QoS pada Jaringan MPLS dengan OSPF pada jaringan IPv6, menunjukkan MPLS dengan OSPF dapat bekerja secara optimal apabila terdapat banyak switching dalam jaringan dan memberikan dampak kualitas yang baik pada delay dan throuhput yang diukur [7]. Penelitian lain pada simulasi traffic MPLS yang dilakukan oleh Mohd. Imran dkk, menunjukkan bahwa simulasi MPLS dapat memberikan keuntungan pada rekayasa traffic dalam jaringan. OSPF dapat digunakan sebagai pengambilan jalur terbaik yang digunakan dalam komunikasi. Dengan penggunaan MPLS menunjukkan tidak hanya mengandalkan jalur terpendek, namun juga memanfaatkan jalur yang kurang dimanfaatkan ketika jalur terpendek digunakan secara berlebihan. [3].

Kemudian pada penelitian oleh Fiade dkk yaitu menganalisis performansi jaringan berbasis pengiriman paket TCP untuk mengukur throughput dan pengiriman paket UDP untuk mengukur jitter dan packet loss yang diterapkan pada jaringan utama, serta parameter delay untuk mengukur waktu yang dibutuhkan pada saat terjadinya link failover sistem. Tujuannya untuk mencapai dan meningkatkan kinerja pada jaringan yang kompleks, stabil dan ketersediaan, diperlukan sistem link Failover dimana terdapat gangguan pada link utama dan dapat diteruskan melalui tautan cadangan yang telah diterapkan ke setiap protokol perutean. Penelitian ini dilakukan dengan simulator GNS3 pada routing BGP. Hasil menunjukkan bahwa protokol OSPF mampu dengan cepat menyelesaikan masalah ketika jaringan terputus atau down dengan nilai waktu respon yang tercepat dibanding beberapa protokol lain seperti RIP dan EIGRP [8].

Penelitian ini akan memberikan gambaran tentang bagaimana routing OSPF bekerja dengan mengimplementasikan teknologi rekayasa lalu lintas dengan pemberian gangguan pada jaringan menggunakan MPLS [9]. Berdasarkan penelitian sebelumnya yang menggunakan simulator, penelitian memiliki kesamaan yaitu pencarian kualitas jaringan dengan routing MPLS OSPF namun dengan kondisi uji digunakan pada kondisi jaringan yang normal dan 
kondisi jaringan yang terganggu.

Permasalahan yang akan diteliti dalam penelitian ini adalah bagaimana metode MPLS OSPF dalam menghadapi permasalahan gangguan pada jaringan, dan bagaimana kualitas QoS yang dihasilkan pada saat gangguan jaringan terjadi, baik gangguan yang bersifat pembebanan jalur maupun gangguan yang disebabkan pengaruh fisik perangkat jaringan. Penelitian ini akan menggunakan prototipe jaringan menggunakan perangkat nyata dengan Routerboard Mikrotik. Tujuan khusus dari penelitian ini adalah menganalisa bagaimana ketahanan dari routing MPLS OSPF pada saat kondisi jaringan normal dan jaringan mengalami gangguan, dan bagaimana reaksi dari kecepatan waktu konvergensi. Tentunya agar membuat jaringan menjadi lebih baik kinerjanya dalam mengirimkan paket data, dengan mencari rute atau jalur yang terbaik pada topologi jaringan. Sehingga hasil dari penelitian ini dapat menjadi referensi bagi administrator jaringan dalam memilih metode routing untuk diimpelmentasikan pada jaringan yang dikembangkan.

\section{METODE PENELITIAN}

\subsection{Metode Penelitian}

Penelitian ini menggunakan metode eksperimental dengan menggunakan prototipe topologi jaringan dengan menggunakan Routerboard Mikrotik. Metode eksperimental merupakan pendekatan yang digunakan dalam mencari pengaruh perlakuan terhadap kondisi tertentu[10]. Topologi jaringan menggunakan peragkat router sebanyak 8 router yang diatur dengan metode MPLS OSPF, dengan dua PC sebagai client. Gambar 1 menunjukkan rancangan topologi yang digunakan.

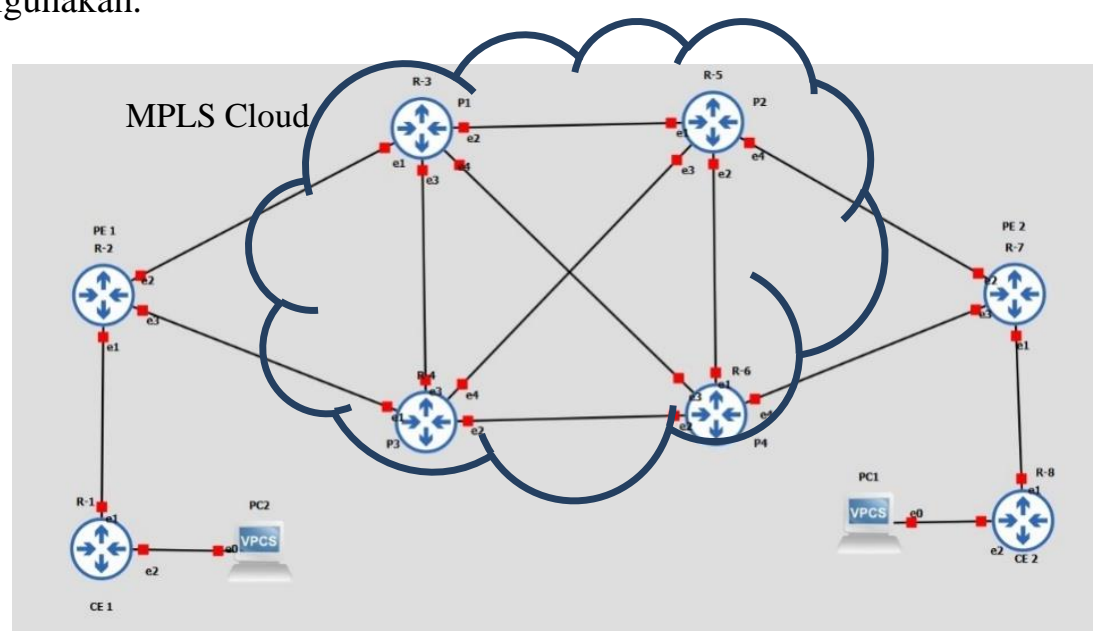

Gambar 1. Topologi jaringan

Simulasi digunakan sesuai dengan Gambar 1 dengan komunikasi dari PC1 ke PC2 secara point-to-point. Dengan memberikan gangguan link failure pada saat komunikasi dilakukan.

\section{a. KonsepQuality of Service (QoS)}

Quality of Service (QoS) dalam Iqbal dkk. (2016), menurut Ferguson dan Huston merupakan metode pengukuran tentang seberapa baik jaringan dan merupakan suatu untuk mendefinisikan karakteristik dan sifat dari suatu service [11].

Konsep Quality of Service (QoS) dalam rekomendasi ITU-T E.800 didefinisikan sebagai efek kolektif dari kinerja layanan, yang menentukan tingkat kepuasan pengguna layanan. Quality of Service (QoS) merupakanmetode pengukuran tentang seberapa baikjaringan dan merupakan suatu usaha untukmendefinisikan karakteristik dan sifat dari satuservis. QoS digunakan untuk mengukursekumpulan atribut kinerja yang telahdispesifikasikan dan diasosiasikan dengan suatuservis.Standar metrik formal dalam pengukuran QoS pada jaringan meliputi Ketersediaan layanan (availability), waktu jeda (delay), variasi delay atau jitter, throughput dan packet loss [12]. Parameter QoS yang digunakan sebagai berikut: 
i. $\quad$ Latency/Delay

Delay merupakan waktu yang dibutuhkan paket untuk mencapai tujuan dalam arsitektur jaringan, karena adanya antrian, atau mengambil rute lain untuk menghindari kemacetan[11][13]. Menurut versi TIPHON (Telecommunication and Internet Protocol Harmonization Over Network) standarisasi nilai delay dapat dilihat pada Tabel 1.

Tabel 1 Standarisasi nilai delay versi TIPHON

\begin{tabular}{|l|c|}
\hline \multicolumn{1}{|c|}{ Kategori Delay } & Besar Delay \\
\hline Sangat Bagus & $<150$ milidetik \\
\hline Bagus & $150 \mathrm{~s} / \mathrm{d} 300$ milidetik \\
\hline Sedang & $300 \mathrm{~s} / \mathrm{d} 450$ milidetik \\
\hline Buruk & $>450$ milidetik \\
\hline
\end{tabular}

Untuk mengukur nilai delay digunakan persamaan (1):

ii. $\quad$ Jitter

$$
\text { Rata-rata Delay }=\frac{\text { Total Delay }}{\text { Total Paket diterima }}
$$

Jitter merupakan penundaan perpariasi dari waktu ke waktu, Jitter disebut sebagai perubahan variasi delay pada suatu periode. Standarisasi nilai jitter menurut TIPHON dapat dilihat pada Tabel 2 dan utuk melakukan perhitungan jitter dapat menggunakan persamaan (2).

Tabel 2 Standarisasi nilai jitter versi TIPHON

\begin{tabular}{|l|c|}
\hline \multicolumn{1}{|c|}{ Kategori Degradasi } & Peak Jitter \\
\hline Sangat Bagus & 0 milidetik \\
\hline Bagus & $0 \mathrm{~s} / \mathrm{d} 75$ milidetik \\
\hline Sedang & $76 \mathrm{~s} / \mathrm{d} 125$ milidetik \\
\hline Buruk & $126>225$ milidetik \\
\hline
\end{tabular}

$$
\text { Jitter }=\frac{\text { Total Variasi Delay }}{\text { Total paket yang diterima }}
$$

iii. $\quad$ Packet Loss

Packetloss didefinisikan sebagai kegagalan transmisi paket data mencapai tujuannya [11]. Standarisasi nilai packet loss menurut TIPHON dapat dilihat pada Tabel 3.

Tabel 3 Standarisasi nilai packet loss versi TIPHON

\begin{tabular}{|l|c|}
\hline \multicolumn{1}{|c|}{ Kategori Degradasi } & Packet Loss \\
\hline Sangat Bagus & 0 milidetik \\
\hline Bagus & $0 \mathrm{~s} / \mathrm{d} 75$ milidetik \\
\hline Sedang & $76 \mathrm{~s} / \mathrm{d} 125$ milidetik \\
\hline Buruk & $126>225$ milidetik \\
\hline
\end{tabular}

Dengan perhitungan packet loss menggunakan persamaan (4).

$$
\text { Packet Loss }=\frac{\text { Paket dikirim }- \text { Paket diterima }}{\text { Paket dikirim }} \times 100 \%
$$


iv. Throughput

Throughput adalah kemampuan sebenarnya suatu jaringan dalam melakukan pengiriman data. Throughput merupakan jumlah total kedatangan paket yang sukses yang diamati pada destination selama interval waktu tertentu dibagi oleh durasi interval waktu tersebut[11]. Perhitungan nilai throughput dapat menggunakan persamaan (4).

$$
\text { Throughput }=\frac{\text { Jumlah data yang dikirim }}{\text { Waktu pengiriman data }}
$$

\section{b. Konsep MPLS}

Dalam arti tertentu, aliran MPLS serupa dengan konsep sirkuit virtual yang digunakan untuk teknologi seperti ATM. Teknologi MPLS memungkinkan tingkat QoS pada tingkat tertentu untuk setiap aliran dan penyederhanaan penerusan paket oleh router[14]. MPLS mengijinkan router yang berada di edge network untuk menyisipkan label yang simple ke dalam sebuah paket [15].

MPLS dideskripsikan sebagai kumpulan node yang berdekatan yang mengoperasikan routing dan forwarding. MPLS bekerja sesuai dengan petunjuk label dan dapat dibagi menjadi MPLS core dan MPLS edge. Setiap Paket yang masuk ke MPLS edge dimasukkan ke dalam paket MPLS dan diteruskan dalam MPLS core hingga mencapai simpul tujuannya.

\section{c. Failover link System}

Failover digunakan untuk meningkatkan availability dari layanan jaringan.Metode failover digunakan untuk mencegah terjadinya kegagalan fungsi [16]. Kesalahan link atau failover link dapat dibagi menjadi dua kategori atau mode, yaitu Active/Passive Failover dan Active/Active failover. Pada mode active/passive, tidak semua node jaringan berstatus aktif namun hanya node yang digunakan saja yang aktif. Apabila mengalami deteksi gangguan pada node aktif, barulah node pasif akan menjadi aktif untuk mengambil alih task yang sedang dikerjakan. Sedangkan pada Active/Active failover, semua node bersifat aktif dan akan langsung mengambil alih task pada node yg mengalami gangguan. Tujuannya untuk melakukan load balancing pada jaringan komputer yang digunakan [8].

\section{d. Skenario Pengujian}

Pengujian dilakukan untuk meilhat bagaimana metode MPLS OSPF berkerja dan berkomunikasi pada saat terjadi gangguan link failure. Pengujian ini dilakukan dengan melakukan komunikasi transferdata antara client 1 dengan client 2 . Selain itu, untuk membantu menganalisa komunikasi yang terjadi, digunakan tools network analyzer Wireshark.

Skenario pengujian yang dilakukan antara lain:

a. Pengujian dengan menggunakan transfer file protocol TCP.

b. Pengujian dilakukan dengan kondisi normal tanpa gangguan sebagai acuan kondisi lainnya.

c. Pengujian dengan memberikan gangguan pada saat proses komunikasi berupa putus jalur atau link failure.

d. Pemutusan jalur dibuat dalam 3 tahap pemutusan.

e. Pengujian dilakukan dengan perekaman komunikasi melalui wireshark.

Agar mendapatkan hasil yang lebih menunjukkan pengaruh gangguan, maka pengujian akan dilakukan sebanyak lima kali pada kondisi masing-masing pengujian. 


\section{HASIL DAN PEMBAHASAN}

Berdasarkan hasil pengujian yang dilakukan, didapat penilaian dengan parameter Quality of Service (QoS) yang diuji yaitu delay, jitter, packet loss, dan throughput. Pengujian dilakukan sebanyak 5 kali masing-masing pada kondisi normal, 1 link failure, 2 link failure dan 3 link failure. Kemudian diambil rata-rata nilai sebagai nilai pembanding antar masing-masing kondisi, tujuannya untuk melihat bagaimana kualitas QoS dari jaringan tersebut. Hasil pengujian yang dilakukan sebagai berikut.

\subsection{Hasil Pengujian Delay}

Hasil pengujian delay yang telah dilakukan dapat dilihat pada Tabel 4.

Tabel 4. Hasil Pengujian Delay

\begin{tabular}{|l|c|c|c|c|c|c|}
\hline \multicolumn{7}{|c|}{ MPLS OSPF (milidetik) } \\
\hline Kondisi Uji & Uji 1 & Uji 2 & Uji 3 & Uji 4 & Uji 5 & $\begin{array}{c}\text { Rata } \\
\text { Nilai }\end{array}$ \\
\hline Normal & 0.229 & 0.213 & 0.198 & 0.173 & 0.205 & 0.204 \\
\hline 1 Fail Link & 0.185 & 0.273 & 0.173 & 0.162 & 0.204 & 0.199 \\
\hline 2 Fail Link & 0.144 & 0.174 & 0.136 & 0.140 & 0.136 & 0.146 \\
\hline 3 Fail Link & 0.876 & 1.012 & 0.911 & 1.001 & 0.934 & 0.947 \\
\hline
\end{tabular}

Untuk melihat perbandingan antara masing-masing kondisi pada pengujian delay, dapat dilihat pada grafik yang disajikan pada Gambar 2.

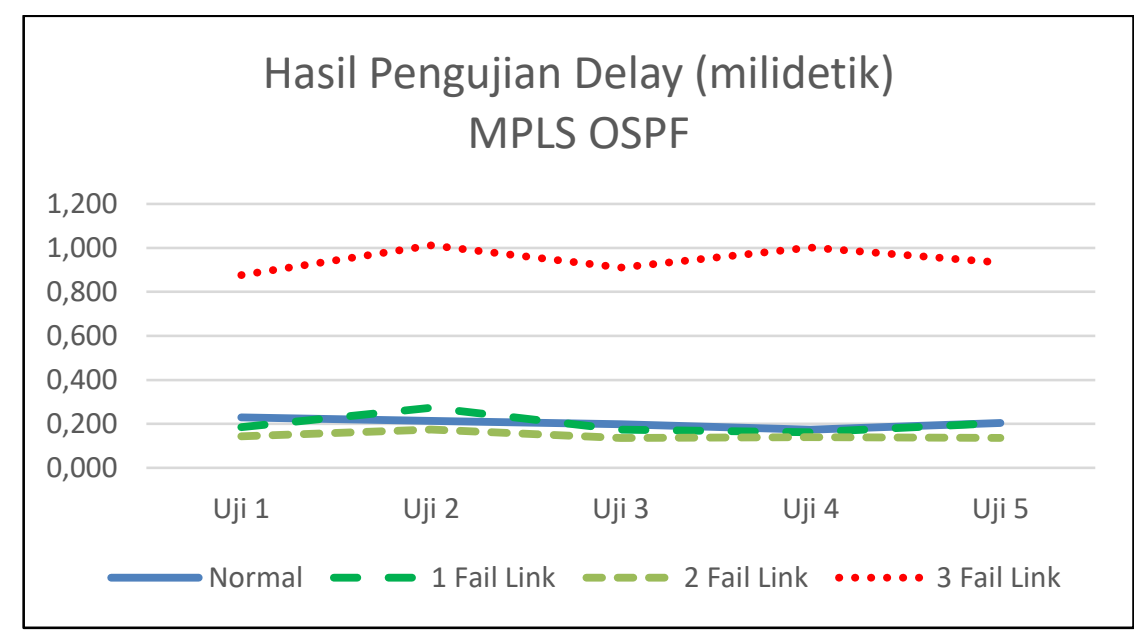

Gambar 2. Grafik hasil pengujian delay.

Pada Gambar 2 dapat dilihat bahwa terjadi perubahan nilai antara kondisi normal dengan kondisi link failure terjadi. Pada kondisi normal, terlihat rata nilai delay lebih stabil dan tidak terlalu berbeda pada saat terjadi gangguan 1 link failure dan 2 link failure. Namun pada kondisi 3 link failure, terlihat perbedaan yang signifikan dibanding kondisi lainnya. Walaupun terdapat kenaikan nilai delay, namun masih dikatakan dalam kondisi baik dalam rentan 1 milidetik. 
a. Hasil Pengujian Jitter

Pengujian jitter pada penelitian ini dapat dilihat pada Tabel 5.

Tabel 5. Hasil pengujian jitter

\begin{tabular}{|l|c|c|c|c|c|c|}
\hline \multicolumn{7}{|c|}{ MPLS OSPF (milidetik) } \\
\hline $\begin{array}{c}\text { Kondisi } \\
\text { Uji }\end{array}$ & Uji 1 & Uji 2 & Uji 3 & Uji 4 & Uji 5 & $\begin{array}{c}\text { Rata } \\
\text { Nilai }\end{array}$ \\
\hline Normal & -0.016 & 0.112 & 0.000 & 0.000 & 0.000 & 0.019 \\
\hline 1 Fail Link & 0.001 & 0.002 & 0.002 & 0.001 & 0.001 & 0.001 \\
\hline 2 Fail Link & 0.002 & 0.064 & 0.002 & 0.003 & 0.003 & 0.015 \\
\hline 3 Fail Link & 0.229 & 0.168 & 0.198 & 0.173 & 0.205 & 0.195 \\
\hline
\end{tabular}

Agar perbandingan jitter yang dihasilkan pada masing-masing pengujian dapat dilihat secara jelas pada grafik pada Gambar 3.

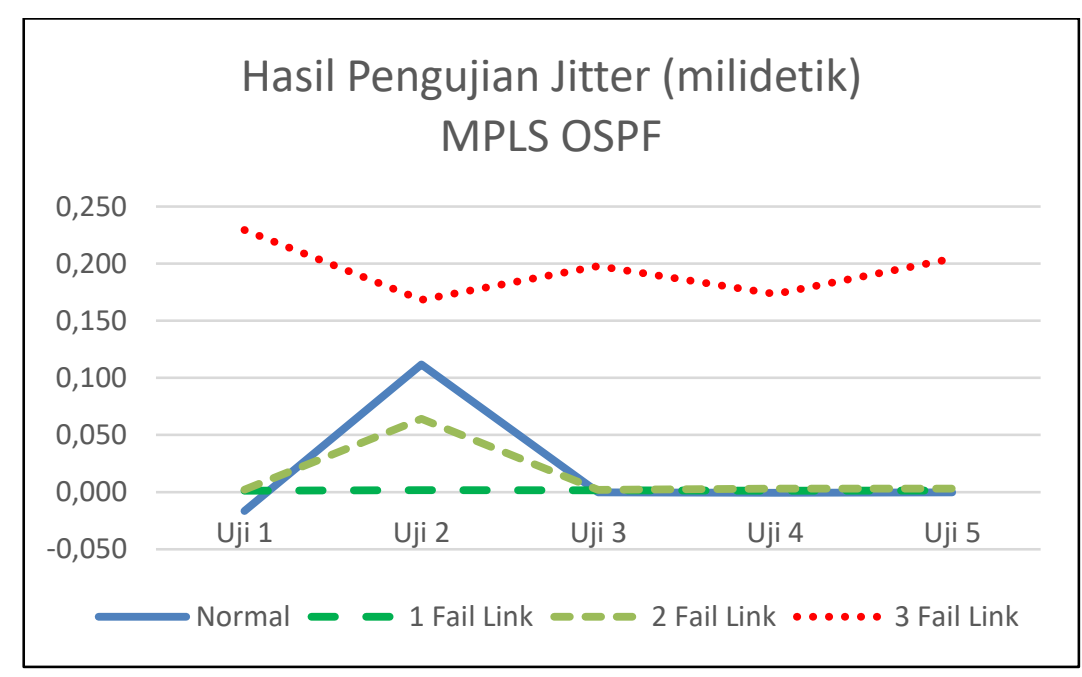

Gambar 3. Grafik hasil pengujian jitter

Gambar 3 menunjukkan adanya perubahan nilai pada kondisi uji 2 dimana pada kondisi normal dan kondisi 2 link failure terdapat kenaikan, namun pada kondisi 3 link failure terdapat penurunan. Namun dari grafik didapat nilai jitter paling besar terdapat pada kondisi 3 link failure. 
b. Hasil Pengujian Packet Loss

Hasil packet loss yang didapat dari hasil pengujian dapat dilihat pada Tabel 6

Tabel 6. Hasil pengujian packet loss

\begin{tabular}{|l|c|c|c|c|c|c|}
\hline \multicolumn{7}{|c|}{ MPLS OSPF (\%) } \\
\hline $\begin{array}{c}\text { Kondisi } \\
\text { Uji }\end{array}$ & Uji 1 & Uji 2 & Uji 3 & Uji 4 & Uji 5 & $\begin{array}{c}\text { Rata } \\
\text { Nilai }\end{array}$ \\
\hline Normal & 0.117 & 0.106 & 0.081 & 0.117 & 0.094 & 0.103 \\
\hline 1 Fail Link & 2.377 & 0.224 & 1.355 & 0.852 & 0.674 & 1.097 \\
\hline 2 Fail Link & 2.082 & 2.484 & 1.426 & 1.171 & 1.415 & 1.716 \\
\hline 3 Fail Link & 1.148 & 2.666 & 3.279 & 6.875 & 11.595 & 5.112 \\
\hline
\end{tabular}

Grafik perbandingan hasil packetloss dapat dilihat pada Gambar 4.

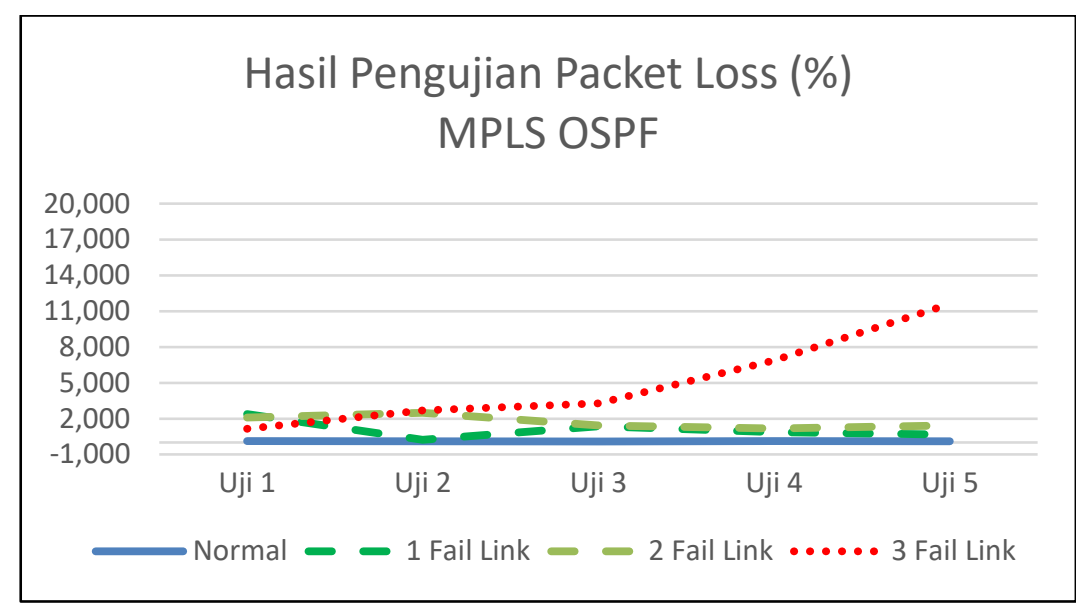

Gambar 4. Grafik hasil pengujian packet loss

Pada grafik di Gambar 4 terdapat kondisi packet loss yang semakin meningkat ketika terjadi gangguan link failure pada jaringan. Semakin banyaknya link failure yang terjadi, makan menyebabkan semakin tinggi nilai packet loss yang didapatkan.

c. Hasil Pengujian Throughput

Hasil pengujian parameter throughput yang didapat dapat dilihat pada Tabel 7.

Tabel 7. Hasil pengujian throughput

\begin{tabular}{|l|r|r|r|r|r|r|}
\hline \multicolumn{7}{|c|}{ MPLS OSPF (mbps) } \\
\hline Kondisi Uji & Uji 1 & Uji 2 & Uji 3 & Uji 4 & Uji 5 & $\begin{array}{c}\text { Rata } \\
\text { Nilai }\end{array}$ \\
\hline Normal & 94 & 77 & 93 & 90 & 77 & 86.2 \\
\hline Putus 1 router & 54 & 38 & 59 & 65 & 47 & 52.6 \\
\hline Putus 2 router & 73 & 44 & 50 & 70 & 40 & 55.4 \\
\hline Putus 3 router & 61 & 50 & 49 & 58 & 51 & 53.8 \\
\hline
\end{tabular}

Grafik pembanding hasil uji throughput dapat dilihat pada Gambar 5. 


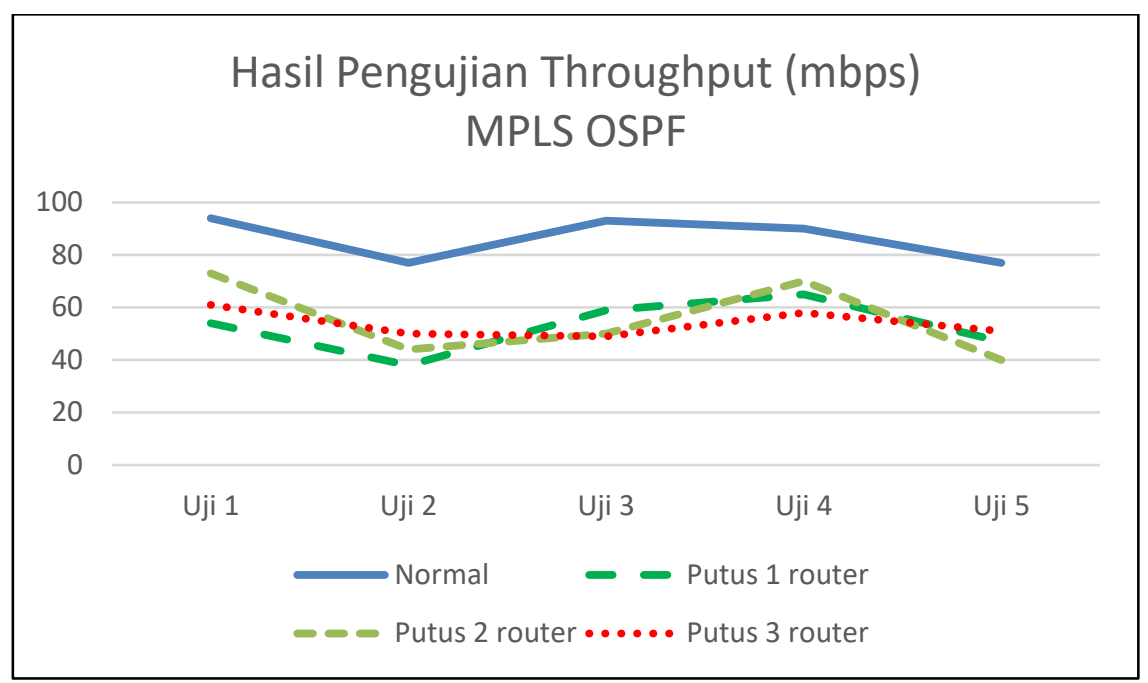

Gambar 5. Grafik hasil pengujian throughput.

Pada grafik yang dihasilkan, dapat dilihat bahwa semakin banyak gangguan link failureyang terjadi, maka semakin menurunkan nilai throughput dibandingkan dengan kondisi pengujian normal.

\section{KESIMPULAN DAN SARAN}

Berdasarkan hasil pengujian yang dilakukan dengan parameter QoS metode MPLS OSPF memiliki hasil sebagai berikut:

- Pengaruh gangguan link failure pada jalur jaringan secara bertahap memberikan hasil yang berbeda pada parameter QoS, dibandingkan dengan kondisi normal.

- Penggunaan Data protocol TCPdengan sifatconnection oriented membuat pengiriman data tetap berjalan sampai terkirim walau dilakukan gangguan link failure.

- Routing protocol MPLS OSPF menghasilkan kinerja baik pada parameter delay dengan nilai delay terbesar yang didapat 11 milidetik dan memiliki penurunan throughput pada saat dilakukan gangguan link failure.

- Berdasarkan hasil yang didapat, penggunaan metode routing MPLS OSPF dapat menjadi referensi administrator jaringan untuk diimplementasikan pada jaringan yang digunakan.

Saran yang dapat dilakukan pada penelitian selanjutnya adalah bagaimana kualitas QoS MPLS OSPF terhadapat gangguan link failure dan pembebanan pada kondisi topologi yang lebih besar, atau dengan perangkat router yang lebih banyak.

\section{UCAPAN TERIMA KASIH}

Puji syukur penulis panjatkan kepada Allah SWT yang senantiasa memberikan rahmat dan karunia-Nya yang telah dilimpahkan sehingga penulis dapat menyelesaikan penelitian ini. Tidak lupa pula saya ucapkan terima kasih kepada Kementerian Riset dan Teknologi / Badan Riset dan Inovasi Nasional Republik Indonesia (Ristek Brin) yang memberikan kesempatan, dukungan moril, materil dan mengembangkan kemampuan sebagai Dosen Pemula

\section{DAFTAR PUSTAKA}

[1] I. Nurhaida, D. Widya, P. Pratama, R. A. M. Zen, and H. Wei, "Interior Gateway Protocol Routing Performance Comparison of The Virtual Private Network Based On Multi Protocol Label Switching And Direct-Link Backup,” vol. 24, no. 1, pp. 1-10, 2020. 
[2] C. Duta, L. Gheorghe, and N. Tapus, "Analyze OSPF Convergence Time in the Presence of Single and Multiple Failures," Emerg. 2015 Seventh Int. Conf. Emerg. Networks Syst. Intell., pp. 72-78, 2015.

[3] M. Imran, M. A. Khan, and M. A. Qadeer, "Design and Simulation of Traffic Engineering using MPLS in GNS3 Environment," no. ICCMC, pp. 1026-1030, 2018.

[4] R. Adrian, A. Dahlan, and K. Anam, "OSPF Cost Impact Analysis on SDN Network," Inf. Syst. Electr. Eng. (ICITISEE), 2nd Int. Conf. Inf. Technol., pp. 198-201, 2017.

[5] R. A. Larrea-luzuriaga, J. M. Jimenez, S. Sendra, and J. Lloret, "Comparative Study of Routing Protocols in Ring Topologies using GNS3," Elev. Int. Conf. Internet Monit. Prot., pp. 38-44, 2016.

[6] B. Anupkumar, M, N. N, and L. S. Jyothi, "Traffic Prioritazation in MPLS Enabled OSPF Network," IEEE, vol. 6, no. World Congress on Information and Communication Technologies, pp. 132-137, 2012.

[7] I. D. Rahmawati, A. Shaleh, I. Winarno, M. Politeknik, E. Negeri, and J. T. Telekomunikasi, "Analisa QoS Pada Jaringan MPLS Ipv6 Berbasis Routing OSPF," Yogyakarta, 2011.

[8] A. Fiade, A. Agustian, U. Masruroh, and A. F. L. System, "Analysis of Failover Link System Performance in OSPF , EIGRP, RIPV2 Routing Protocol with BGP," in The 7th International Conference on Cyber and IT Service Management (CITSM), 2019.

[9] M. Taruk and E. Budiman, "OSPF WIRELESS MESH WITH MPLS TRAFFIC ENGINEERING," pp. 4-7, 2019.

[10] Y. Pribadi, A. B. Pn, and M. A. Irwansyah, "Analysis of the Use of the Failover Clustering Method to Achieve High Availability on a Web Server ( Case Study: Informatics Department Building ) Analysis of the Use of the Failover Clustering Method to Achieve High Availability on a Web Server ( Case S," J. Sist. dan Teknol. Inf., vol. 8, no. 2, pp. 218-229, 2020.

[11] M. Iqbal, M. Rifqi, and Amarudin, "Anilisis Perbandingan QoS (Quality of Service) Pada Routing Protocol OSPF dan BGP Menggunakan Mikrotik," in Proceedings Seminar Nasional Riset Ilmu Komputer (SNRIK) Universitas Muslim Indonesia, 2016, p. 47.

[12] F. Hasanul, "Analisis Qos (Quality of Service) Pengukuran Delay, Jitter, Packet Lost Dan Throughput Untuk Mendapatkan Kualitas Kerja Radio Streaming Yang Baik," Teknol. Inf. dan Komun., vol. 7, no. 2, pp. 98-105, 2018.

[13] A. A. Qayyum, M. Zulfiqar, and M. Abrar, "Quality of Service Performance Analysis of Voice over IP in Converged MPLS Networks," IEEE, pp. 8-11, 2020.

[14] K. Mirzahossein, M. Nguyen, and S. Elmasry, "School of Engineering Science FINAL PROJECT : Analysis of RIP , OSPF , and EIGRP Routing Protocols using OPNET," ENSC 427 Commun. NETWORKS, 2013.

[15] A. Kahfi and P. W. Purnawan, "Simulasi dan Analisis QoS pada Jaringan MPLS IPv4 dan IPv6 Berbasis Routing OSPF," J. Maest., vol. 1, no. April, pp. 73-79, 2018.

[16] W. Adhiwibowo, A. R. Irawan, F. Teknologi, and K. Universitas, "IMPLEMENTASI REDUNDANT LINK UNTUK MENGATASI," Pengemb. Rekayasa dan Teknol., vol. 15, no. 1, pp. 48-53, 2019. 